\title{
Prognostic role of microRNA-155 in various carcinomas: Results from a meta-analysis
}

\author{
Jing He ${ }^{\mathrm{b}, 1}$, Fengmei Zhang ${ }^{\mathrm{b}, 1}$, Ying $\mathrm{Wu}^{\mathrm{b}}$, Wei Zhang ${ }^{\mathrm{b}}$, Xiaoli Zhu ${ }^{\mathrm{c}}$, Xuelian $\mathrm{He}^{\mathrm{d}}$, Yuhang Zhao ${ }^{\mathrm{e}}$, \\ Wei Zhang ${ }^{\mathrm{b}, *}$ and Yulan Zhao ${ }^{\mathrm{a}, *}$ \\ ${ }^{a}$ School of Life Science, East China Normal University, Shanghai, China \\ ${ }^{\mathrm{b}}$ Institutes for Advanced Interdisciplinary Research, East China Normal University, Shanghai, China \\ ${ }^{\mathrm{c}}$ Department of Otorhinolaryngology, Peking Union Medical College Hospital, Beijing, China \\ ${ }^{\mathrm{d}}$ Central Laboratory, Wuhan Children's Hospital, Wuhan, Hubei, China \\ e Shanghai Integrated Circuit Research and Development Center, Shanghai, China
}

\begin{abstract}
.
BACKGROUND: Recent studies have shown that microRNAs (miRNA) have prognostic values in cancers. This meta-analysis seeks to summarize the global predicting role of miR-155 for survival in patients with a variety of carcinomas.

METHODS: Eligible studies were identified through multiple search strategies. Data were extracted from studies investigating the relationship between miR-155 expression and survival in cancer patients. Combined hazard ratios (HRs) of miR-155 for outcome were analyzed.

RESULTS: A total of 16 studies dealing with various carcinomas were included for this meta-analysis. For overall survival, higher miR-155 expression could significantly predict worse outcome with the pooled HR of 2.057 (95\% CI: 1.392-3.039). For relapse or progress-free survival, elevated miR-155 was also a significant predictor, with a combined HR of 1.918 (95\% CI: 1.311-2.806,). In addition, subgroup analysis showed that higher expression of miR-155 had the trends to predict worse outcome in lung cancer. However, the HRs did not reach the statistical significance.

CONCLUSION: Our findings suggest that miR-155 detection has a prognostic value in cancer patients. Regularly measuring miR-155 expression may be useful in clinical practice.
\end{abstract}

Keywords: miR-155, cancer, prognosis, clinical

\section{Introduction}

MicroRNA (miRNA), a class of highly conserved noncoding RNAs with 19-22 nucleotides, are related with different kinds of diseases, especially cancers [1]. Among all uncovered miRNAs, miR-155 is no doubt

\footnotetext{
*Corresponding authors: Yulan Zhao, School of Life Science, East China Normal University, North Zhongshan Road \#3663, Shanghai 200062, China. Tel.: +86 21 62237225; Fax: +86 21 62237226; E-mail: ylzhao@imet.ecnu.edu.cn; Wei Zhang, $\mathrm{PhD}$, Institutes for Advanced Interdisciplinary Research, East China Normal University, North Zhongshan Road \#3663, Shanghai 200062, China. Tel.: +86 21 54344755; Fax: +86 21 54344755; E-mail: wzhang@sat.ecnu.edu.cn.

${ }^{1}$ Both authors contributed equally.
}

one of the most attractive miRNAs [2]. In recent years, miR-21 and miR-155 were investigated in many clinical studies and both of them were found to have potential prognostic value. miR-155 is initially generated from an exon of a noncoding RNA transcribed from B cell Integration Cluster located on chromosome $21[3,4]$. miR-155 has been found to be upregulated in several types of B cell lymphomas [5]. Some studies demonstrated that miR-155 could act as an oncogene to contribute to multiple facets of tumorigenesis, such as proliferation, motility, invasion, differentiation, angiogenesis, etc. [6-9]. Consistently, silencing of miR-155 could inhibit apoptosis, proliferation and migration in cancer cells [10].

In clinical studies, miR-155 was reported to be 
associated with lymphoma, leukemia, lung cancer, esophageal cancer, colorectal cancer, breast cancer and other carcinomas $[5,9,11,12]$. Aberrant expression of miR-155 may be a potential diagnostic biomarker of several types of cancers. Interestingly, miR-155 was recently revealed to have prognostic value in some retrospective or prospective studies. For instance, Chen et al., Greither et al., Han et al., Shibuya et al. and Yanaihara et al. reported higher expression of miR-155 indicating poorer survival in various cancers with hazard ratios (HR) more than 1 and $\mathrm{P}$ values less than 0.05 [7,13-16]. However, other studies presented different results. For example, Heegaard et al. reported miR-155 could only insignificantly predict outcome with HR more than 1 but $P$ values more than 0.05 [17]. Moreover, a study recruiting 637 lung cancer patients even suggested higher miR-155 expression may indicate better survival but the trend did not reach significance $(P=0.39)$ [18]. Therefore, it is necessary to conduct a systematic review and meta-analysis to summarize the findings globally and address the inconsistencies of literature.

In this study, we seek to carry out a systematic review and meta-analysis to evaluate the overall risk of miR-155 for survival in patients with cancers, especially lung cancer. We also discuss the possibility to use miR-155 as a prognostic marker in terms of clinical practice and statistics.

\section{Materials and methods}

We performed meta-analysis following the guidelines of the Meta-analysis of Observational Studies in Epidemiology group (MOOSE) [19].

\subsection{Search strategy}

To identify the relevant studies, we searched through the online PubMed and EMBASE database from 1966 to January, 2013. Three sets of key words were used among that process, namely "miR-155 and cancer prognosis", "miR-155 and cancer" and "microRNA and cancer prognosis". By using these 3 sets of key words, the search field was extended and all the relevant studies could be included. Studies were regarded eligible when they investigated the associations between outcome and miR-155. Non-English articles, review articles or letters were excluded. If a study examined the effects of miR- 155 on cancer outcome without reporting hazard ratio value or showing survival curve,

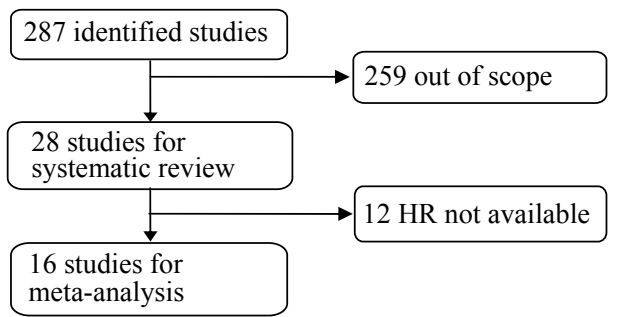

Fig. 1. Flow diagram of the study selection process.

it was still kept in systematic review but not included in the meta-analysis. When there were duplicate studies for the same population, we included in our systematic review the one having reported HRs, or involving more patients (usually the latest). Only in this way could the overlapping between cohorts and overestimation of the overall HR be avoided.

A flow diagram of the study selection process is presented in Fig. 1.

\subsection{Quality assessment}

According to a critical review checklist of the Dutch Cochrane Centre proposed by MOOSE, we systematically assessed the quality of all the studies included [19]. The key points of the current checklist include 1) clear definition of study population and origin of country, 2) clear definition of study design, 3) clear definition of type of carcinoma, 4) clear definition of outcome assessment, 5) clear definition of measurement of miR-155 and 6) sufficient follow-up duration, at least 12 months. If a study did not mention all these six points, it was excluded so as not to compromise the quality of the meta-analysis.

\subsection{Data extraction and conversion}

The extracted data elements of this review included: 1) publication details: first author's last name, publication year, and origin of the studied population; 2) study design; 3) characteristics of the studied population: sample size, age, gender, disease, therapy, and cut-off of miR-155 expression; and 4) HR of elevated miR-155 expression for survival, as well as their $95 \%$ confidence interval (CI) and $\mathrm{P}$ value. When data were only available as Kaplan-Meier curves, data were extracted from the graphical survival plots and estimation of the HR was then performed using the described method [20]. 
Table 1

Summary table of the 16 included studies and the 12 studies lack of HR data. Study design is described as prospective (P), or retrospective (R). NSCLC: non-small cell lung cancer; PDAC: pancreatic ductal adenocarcinoma; HCC: hepatocellular carcinoma; SCC: squamous cell carcinomas;SCLC: small cell lung cancer; CLL: chronic lymphocytic leukemia; DLBCL: diffuse large B cell lymphoma; ESCC: esophageal squamouscell carcinoma; IPMN: intraductal papillary mucinous neoplasms; qRT-PCR: quantitative real-time PCR; ISH: in situ hybridization; OS: overall survival; CSS: cancer-specific survival; DSS: disease-specific survival; DFS: disease-free survival; RFS: relapse-free survival; PFS: progress-free survival; TFS: treatment-free survival; SC: survival curve; AP: author provided; -: not reported

\begin{tabular}{|c|c|c|c|c|c|c|c|c|c|}
\hline & $\begin{array}{l}\text { Origin of } \\
\text { population }\end{array}$ & $\begin{array}{l}\text { Study } \\
\text { design }\end{array}$ & Disease & $\mathrm{N}$ & $\begin{array}{l}\text { miR-155 } \\
\text { assay }\end{array}$ & Cut-off & $\begin{array}{l}\text { Survival } \\
\text { analysis }\end{array}$ & $\begin{array}{c}\text { HR } \\
\text { statistics }\end{array}$ & $\begin{array}{c}\text { Follow-up, } \\
\text { months }\end{array}$ \\
\hline Chen 2011 & China & $P$ & breast cancer & 92 & RT-PCR & median & OS,DFS & $\mathrm{SC}$ & 60 \\
\hline Donnem 2011 & Norway & $\mathrm{P}$ & NSCLC & 335 & ISH & median & CSS & $\mathrm{SC}$ & $48-216$ \\
\hline Greither 2010 & Germany & $\mathrm{P}$ & PDAC & 55 & qRT-PCR & median & OS & reported & $15.9(1-61)$ \\
\hline Han 2011 & China & $\mathrm{P}$ & $\mathrm{HCC}$ & 100 & qRT-PCR & median & OS, RFS & reported & 100 \\
\hline Heegaard 2011 & USA & $\mathrm{P}$ & NSCLC & 215 & $\begin{array}{l}\text { qRT-PCR, } \\
\text { plasma }\end{array}$ & median & OS & AP & 60 \\
\hline Huang 2012 & Taiwan, China & $\mathrm{P}$ & $\mathrm{HCC}$ & 216 & qRT-PCR & median & RFS & reported & 110 \\
\hline Ishihara 2012 & Japan & $\mathrm{P}$ & leukemia & 35 & $\begin{array}{l}\text { qRT-PCR } \\
\text { plasma }\end{array}$ & median & OS & $\mathrm{SC}$ & 33 \\
\hline Lee 2011 & Netherlands & $\mathrm{R}$ & SCLC & 31 & qRT-PCR & median & OS,PFS & AP & 12 \\
\hline Maj 2012 & Poland & $\mathrm{P}$ & mycosis fungoides & 43 & qRT-PCR & median & OS & AP & 156 \\
\hline Papaconstantinou 2012 & Greece & $\mathrm{P}$ & PDAC & 88 & qRT-PCR & median & OS & $\mathrm{SC}$ & 78 \\
\hline Raponi 2009 & USA & $\mathrm{P}$ & lung SCC & 57 & qRT-PCR & median & OS & reported & 60 \\
\hline Rossi 2010 & USA & $\mathrm{P}$ & CLL & 104 & qRT-PCR & median & OS, TFS & reported & 160 \\
\hline Saito 2011 & $\begin{array}{l}\text { USA, Norway, } \\
\text { Japan }\end{array}$ & $\mathrm{R}$ & NSCLC & 317 & qRT-PCR & median & CSS,RFS & reported & 80 \\
\hline Shibuya 2010 & Japan & $\mathrm{P}$ & colorectal cancer & 156 & qRT-PCR & mean & OS,DFS & reported & 60 \\
\hline Voortman 2010 & France, USA & $\mathrm{P}$ & NSCLC & 637 & $\begin{array}{l}\text { qRT-PCR; } \\
\text { ISH }\end{array}$ & median & OS & reported & 96 \\
\hline Yanaihara 2006 & USA & $\mathrm{P}$ & lung cancer & 55 & $\begin{array}{l}\text { microarray, } \\
\text { qRT-PCR }\end{array}$ & median & OS & reported & 60 \\
\hline Caponi 2013 & Italy, UK & $\mathrm{P}$ & IPMN & 77 & qRT-PCR & & & - & \\
\hline Cui 2013 & China & $\mathrm{P}$ & NSCLC & 260 & $\begin{array}{l}\text { qRT-PCR, } \\
\text { serum }\end{array}$ & & & - & \\
\hline Donnem 2012 & Norway & $\mathrm{P}$ & NSCLC & 335 & qRT-PCR & & & - & \\
\hline Hamano 2011 & Japan & $\mathrm{P}$ & esophageal cancer & 98 & qRT-PCR & & & - & \\
\hline Kim 2012 Epub ahead & Korea & $\mathrm{P}$ & gastric cancer & 91 & qRT-PCR & & & - & \\
\hline Kong 2011 & China & $\mathrm{P}$ & PDAC & 35 & $\begin{array}{l}\text { qRT-PCR } \\
\text { serum }\end{array}$ & & & - & \\
\hline Lawrie 2007 & UK & $\mathrm{R}$ & DLBCL & 76 & qRT-PCR & & & - & \\
\hline Lawrie 2008 & UK & $\mathrm{P}$ & DLBCL & 60 & $\begin{array}{l}\text { qRT-PCR } \\
\text { serum }\end{array}$ & & & - & \\
\hline Liu 2012 & China & $P$ & ESCC & 60 & $\begin{array}{l}\text { qRT-PCR, } \\
\text { plasma }\end{array}$ & & & - & \\
\hline Sun 2012 & China & $\mathrm{P}$ & Breast cancer & 103 & $\begin{array}{l}\text { qRT-PCR, } \\
\text { serum }\end{array}$ & & & - & \\
\hline Wang 2010 & China & $\mathrm{R}$ & acute leukemia & 85 & qRT-PCR & & & - & \\
\hline Zhao 2010 & USA & $\mathrm{P}$ & mantle cell lymphoma & 30 & $\begin{array}{l}\text { microarray, } \\
\text { qRT-PCR }\end{array}$ & & & - & \\
\hline
\end{tabular}

\subsection{Statistical analysis}

A test of heterogeneity of combined HRs was conducted using Cochran's Q test and Higgins I-squared statistic. A random effect model (Der Simonian and Laird method) was used if heterogeneity was observed $(P<0.05)$, while the fixed effect model was applied in the absence of between-study heterogeneity $(P \geqslant$ $0.05)$. Publication bias was evaluated using the funnel plot with the Egger's bias indicator test. All analyses were performed on "Stata: Data Analysis and Statistical Software" V10.1 (http://www.stata.com/).

\section{Results}

Two hundred and eighty seven studies for miR-155 were identified from a primary literature search in PubMed. After manually screening the titles, abstracts and key data, 259 records were excluded for not meeting the criteria listed above. Of the 28 reports selected for the systematic review, 12 studies were excluded in the final meta-analysis for lack of key HR value [2132]. The excluded 12 studies commonly focused on other miRNAs and did not analyze the miR-155 data individually. 
Table 2

Comparison of the predicting value of all cancers and lung cancer in patients

\begin{tabular}{llll}
\hline All cancers & OS & DFS/RFS/PFS/TFS & CSS \\
\hline HR & $2.057(1.392-3.039)$ & $1.918(1.311-2.806)$ & $1.485(0.849-2.596)$ \\
Heterogeneity, $P$ value & 0 & 0.015 & 0.047 \\
Model & Random & Random & Random \\
Bias, $P$ value & 0.009 & 0.986 & 0.35 \\
$\mathrm{~N}$ & 1668 & 890 & 461 \\
Study number & 13 & 7 & 2 \\
\hline Lung cancer & OS & PFS/RFS/CSS & \\
\hline HR & $1.244(0.847,1.825)$ & $1.21(0.97,1.51)$ & \\
Heterogeneity, $P$ value & 0.018 & 0.14 & \\
Model & Random & Fixed & \\
Bias, $P$ value & 0.104 & 0.198 & \\
$\mathrm{~N}$ & 995 & 683 & \\
Study & 5 & 3 & \\
\hline
\end{tabular}

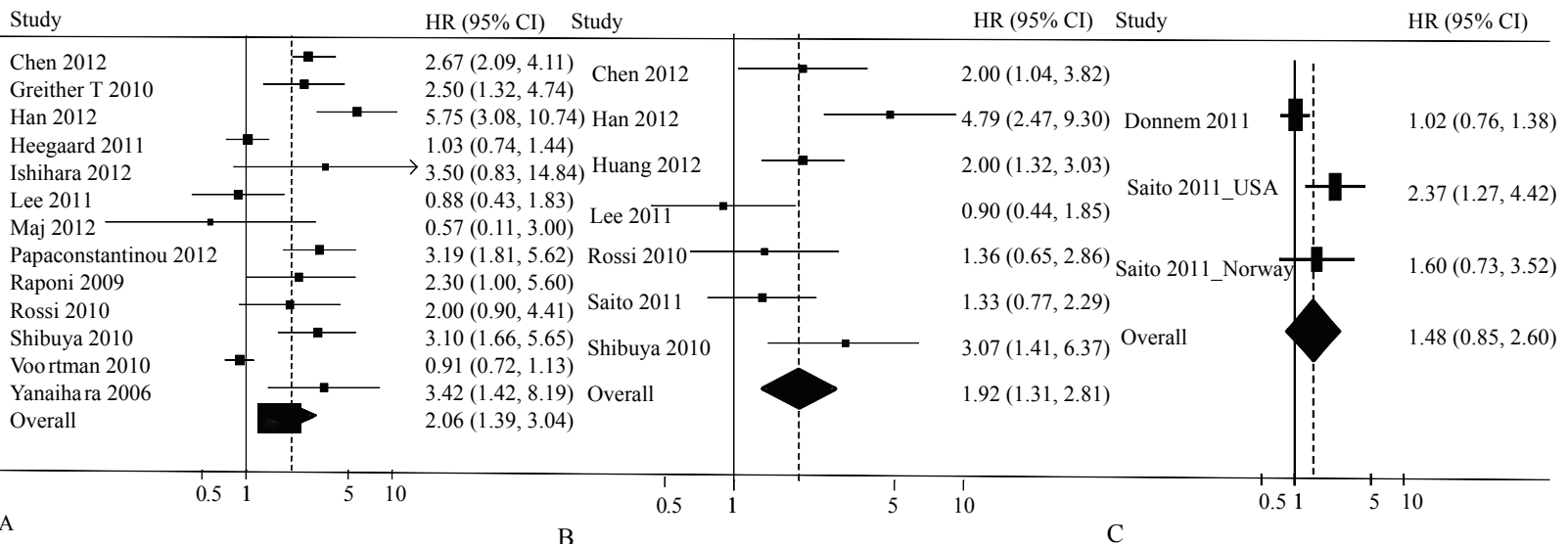

Fig. 2. Forrest plots of studies evaluating hazard ratios of high miR-155 expression as compared to low expression. Survival data are reported as overall survival (A) and disease-free survival (DFS), relapse-free survival (RFS), progress-free survival (PFS) or treatment-free survival (TFS) (B) and cancer-specific survival (CSS) (C).

The main features of 28 relevant studies are summarized in Table 1 . We collected data of 28 studies including a total of 3846 participants from China, France, Germany, Greece, Italy, Japan, Korea, Netherlands, Norway, Poland, United Kingdom and United States of America. Most of them were prospective in design, and four were retrospective. Patients were of a variety of carcinomas, including breast cancer, pancreatic ductal adenocarcinomas, esophageal cancer, hepatocellular carcinoma, leukemia, colorectal cancer, lung cancer and lymphoma. Of all the 28 studies, 16 studies ( $n=2536$ ) with HR data could be included for metaanalysis [7,13-18,33-41]. Among them, seven studies ( $n=1678)$ recruited lung cancer patients. Although quantitative real-time PCR (qRT-PCR) was the widely used methods for miR-155 expression assessment, in situ hybridization (ISH) was also applied in two studies and microarray in two studies. Cancerous tissues were usually examined to determine miR-155 expres- sion level, while serum samples were tested in two studies and plasma in one. Notably, median was selected as the cut-off value of miR-155 in 15 of the 16 studies and mean was applied in the remaining one study. Median was usually used as the cut-off value as it could divide the patients into two groups with same subject number. Such grouping way could statistically avoid large variance between groups.

For studies evaluating overall survival (OS), there appeared to have heterogeneity among studies for miR-155 $(P<0.05)$. Accordingly, a random model was applied to calculate a pooled HR and its $95 \%$ CI (Table 2). We found that higher expression levels of miR-155 significantly predicted poorer OS, with the pooled HR being 2.057 (95\% CI: 1.392-3.039, Fig. 2(a)). The pooled HR was more significantly predictive than a single HR of each study. For each study, the $P$ value varied from $<0.001$ to 0.877 , and eleven studies had a respective $P$ value more 


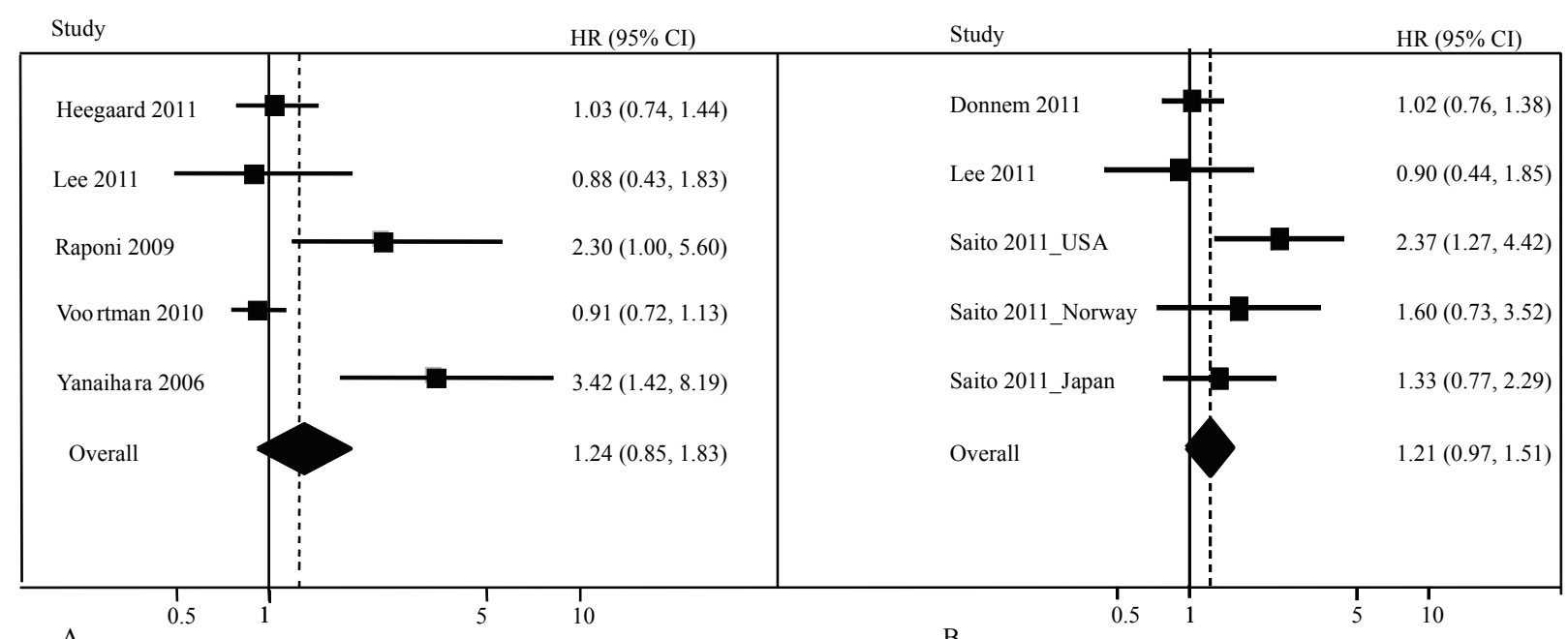

Fig. 3. Forrest plots of OS (A) and PFS/CSS/RFS (B) in lung cancer.
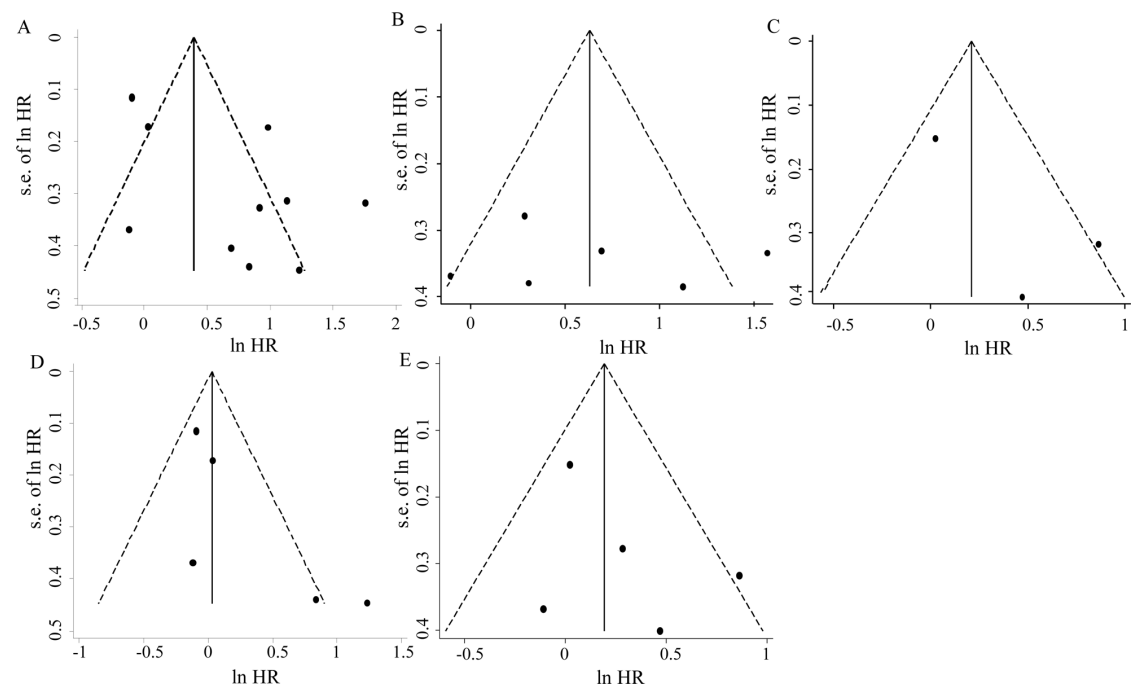

Fig. 4. Funnel plots of studies included in the meta-analyses of all cancers (A-C) and lung cancer (D-E). (A,D): OS; (B): DFS/RFS/ PFS/TFS; (C) CSS; (E) PFS/RFS/CSS.

than 0.05 , which was not statistically significant. For studies evaluating relapse-free/disease-free/progressfree/treatment-free survival (RFS/DFS/PFS/TFS) or cancer-specific survival (CSS), a random model was also applied due to the heterogeneity among studies (Table 2). The expression of miR-155 was also significantly correlated with RFS/DFS/PFS/TFS, with 1.918 (95\% CI: 1.311-2.806, Fig. 2b) as the combined HR while it was insignificantly correlated with CSS/DSS, with 1.485 (95\% CI: 0.849-2.596, Fig. 2(c)) as HR. Among 16 studies $(n=2536)$ with HR data could be included for this meta-analysis, 7 studies $(n=1678)$ recruited lung cancer patients. Hence we conducted a meta-analysis for this sub-group. Then subgroup analysis was performed in lung cancer. The HR of OS and PFS/CSS/RFS was 1.224 (95\% CI: 0.847-1.825, Fig. 3(a)) and 1.213 (95\% CI: 0.947-1.511, Fig. 3(b)) in patients with lung cancer, respectively. Although the trends were positive, those data were not statistically significant.

Finally, publication bias of the included studies was evaluated by funnel plots and Egger's tests. As shown in Fig. 4, most of the funnel plots were symmetric. In OS, RFS/DFS/PFS/TFS and CSS of all cancers and OS and PFS/CSS/RFS of lung cancer meta-analysis, the $\mathrm{P}$ values of Egger's regression intercepts were 0.009, 
0.986, 0.350, 0.104 and 0.198, respectively. Except for the OS of all cancers, most of the $\mathrm{P}$ values were more than 0.05 (Table 2), therefore, significant publication bias did not exist in four meta-analysis whereas it only existed in OS of all cancers.

\section{Discussion}

This systematic review and meta-analysis showed that elevated miR-155 did predict poor survival in patients with a variety of carcinomas. However, our conclusions should be somewhat tempered. First, though the pooled risks of miR-155 for OS and RFS were significant and quite high with global HRs (2.057 and 1.918), the risk of miR-155 for CSS in cancer patients was insignificant. Moreover, elevated miR-155 could not predict worse outcome in lung cancer patients. The possible cause for the inconsistent results may be the limited number of subjects and studies. Therefore we strongly suggest conducting more prognostic studies for high miR-155 expression in all kinds of carcinomas. Second, a study dealing with more than 600 lung cancer patients, interestingly, predicted an insignificant outcome with HR of 0.91 [18]. As that qualified study showed an opposite trend as our conclusion, cautions should be taken when designing and performing future studies. Third, the studies did not propose clear miR-155 cut-off value. Although most of them defined median as the cut-off of elevated miR-155 expression, the accurate values could be various in the different study populations. Fourth, the current statistical analysis could not elicit miR-155 independently predictive due to methodological limits. Lack of individual HR data of other markers makes it difficult to exclude the influences by confounding factors in a meta-analysis. Finally, as is analysed in Stata software, heterogeneity of subjects and publication bias may also influence the power of our conclusion. Marked heterogeneity of subjects existed in OS, RFS and CSS of all cancers and OS in lung cancer groups. The heterogeneity of the populations was probably due to the difference in baseline characteristics of patients (age, tumor, stage, race or country), disease type, cut-off value of miR155, the duration of follow-up, etc. For example, for CSS/RFS studies, when we stratified them according to tumor type, heterogeneity disappeared in lung cancer subgroup $(P>0.05)$. Since such differences might cause a residual confounding effect on these studies, we attempted to minimize the effect by using a random effect model. Furthermore, significant publication bias was still detected in one of the subgroup meta-analysis. To make up, it is considered as the cut-off of significant difference only if the $\mathrm{p}$ value is less than 0.05 .

Our data demonstrated miR-155 was a promising biomarker of cancers. However, several points need to be considered. First, how do researchers select an appropriate cut-off value to be accurate enough? To date, most of studies used median or mean value in their laboratory or hospital as the cut-off value. Lack of abundant miR-155 expression data in global population leaves it difficult to set a standard cut-off value. Second, which should be used to test, plasma, serum or tissue? Serum and plasma are easy to obtain and convenient to examine in the case of emergency and to be monitored routinely; whereas tissues are widely used resource for miRNA study currently. In this metaanalysis, a comparison of circulating vs. tissue expression of miR-155 was not performed because only 2 studies were dealing with circulating miR-155. More studies should be conducted to compare the prognosis value of tissue miR-155 and circulating miR-155. Third, though data in all cancers are strong or nearly strong, using HR more than 2 as an empirical cutoff value for a strong predictor, the counterparts for a single type of cancer such as lung cancer are not strong. Therefore, particular miRNA for specific cancer remains discovered. For various types of cancer, over 2000 subjects are enough to draw a powerful conclusion. However, if we consider applying miR-155 in prognosis of a single type of cancer, more studies and more subjects are needed.

Other than miR-155, miR-21 is also a widely accepted biomarker of different kinds of cancers like breast cancer and hepatocellular carcinoma [42,43]. Our previous meta-analysis has shown that elevated expression of miR-21 was a predictor for worse outcome in a variety of cancers, especially in digestive system cancers and head and neck cancers [44]. In some studies, miR-155 was combined with miR-21 or a panel of miRNAs to predict survival $[13,14,17,34-37]$. It is interesting and useful to reveal whether combination application of miR-155 with miR-21 or others has more powerful predictive value than a single miR-155 for universal cancers. Another strategy is to assay miR155 with several tissue-specific miRNAs to evaluate prognosis in some specific cancers, such as lung cancer.

In summary, our meta-analysis, representing a quantified synthesis of all eligible studies, has shown that the higher expression of miR-155 is associated with poor survival in patients with diverse types of cancers. 
It could be more valuable if grouping data from different cancer types or from different sample origin. However, it is difficult to perform meta-analysis in subgroups currently due to the limited sample size. Therefore, more clinical studies should be carried out before the application of miR-155 in prognosis of cancer, especially a single type of cancer.

\section{Acknowledgements}

The analysis was supported by National Natural Science Foundation of China (NSFC 30800401). We thank the following persons for their help in the preparation of manuscript: Prof. Lihui Lai, Prof. Jiaying Liu, Miss Xiaorong Zhu and Dr. Zhongshi Liang from East China Normal University and Prof. Chew-Kiat Heng from National University of Singapore. We declare that we have no conflict of interest.

\section{References}

[1] Bartel D P. MicroRNAs: genomics, biogenesis, mechanism, and function. Cell. 2004;116:281-97.

[2] Chang S, Wang R H, Akagi K, Kim K A, Martin B K, Cavallone L, Haines D C, Basik M, Mai P, Poggi E, Isaacs C, Looi L M, Mun K S, Greene M H, Byers S W, Teo S H, Deng C $\mathrm{X}$ and Sharan S K. Tumor suppressor BRCA1 epigenetically controls oncogenic microRNA-155. Nat Med. 2011;17:127582.

[3] Tam W. Identification and characterization of human BIC, a gene on chromosome 21 that encodes a noncoding RNA. Gene. 2001;274:157-67.

[4] Lagos-Quintana M, Rauhut R, Yalcin A, Meyer J, Lendeckel $\mathrm{W}$ and Tuschl T. Identification of tissue-specific microRNAs from mouse. Curr Biol. 2002;12:735-9.

[5] Eis P S, Tam W, Sun L, Chadburn A, Li Z, Gomez M F, Lund $\mathrm{E}$ and Dahlberg J E. Accumulation of miR-155 and BIC RNA in human B cell lymphomas. Proc Natl Acad Sci USA. 2005; 102:3627-32.

[6] Dagan L N, Jiang X, Bhatt S, Cubedo E, Rajewsky K and Lossos I S. miR-155 regulates HGAL expression and increases lymphoma cell motility. Blood. 2012;119:513-20.

[7] Han Z B, Chen H Y, Fan J W, Wu J Y, Tang H M and Peng $\mathrm{Z}$ H. Up-regulation of microRNA-155 promotes cancer cell invasion and predicts poor survival of hepatocellular carcinoma following liver transplantation. J Cancer Res Clin Oncol. 2012;138:153-61.

[8] Xie Q, Chen X, Lu F, Zhang T, Hao M, Wang Y, Zhao J, McCrae M A and Zhuang H. Aberrant expression of microRNA 155 may accelerate cell proliferation by targeting sex-determining region Y box 6 in hepatocellular carcinoma. Cancer. 2012;118:2431-42.

[9] Mattiske S, Suetani R J, Neilsen P M and Callen D F. The oncogenic role of miR-155 in breast cancer. Cancer Epidemiol Biomarkers Prev. 2012;21:1236-43.
[10] Li S, Chen T, Zhong Z, Wang Y, Li Y and Zhao X. microRNA155 silencing inhibits proliferation and migration and induces apoptosis by upregulating BACH1 in renal cancer cells. Mol Med Report. 2012;5:949-54.

[11] Fulci V, Chiaretti S, Goldoni M, Azzalin G, Carucci N, Tavolaro S, Castellano L, Magrelli A, Citarella F, Messina M, Maggio R, Peragine N, Santangelo S, Mauro F R, Landgraf P, Tuschl T, Weir D B, Chien M, Russo J J, Ju J, Sheridan R, Sander C, Zavolan M, Guarini A, Foa R and Macino G. Quantitative technologies establish a novel microRNA profile of chronic lymphocytic leukemia. Blood. 2007;109:4944-51.

[12] Volinia S, Calin G A, Liu C G, Ambs S, Cimmino A, Petrocca F, Visone R, Iorio M, Roldo C, Ferracin M, Prueitt R L, Yanaihara N, Lanza G, Scarpa A, Vecchione A, Negrini M, Harris $\mathrm{C} \mathrm{C}$ and Croce $\mathrm{C} \mathrm{M}$. A microRNA expression signature of human solid tumors defines cancer gene targets. Proc Natl Acad Sci USA. 2006;103:2257-61.

[13] Greither T, Grochola L F, Udelnow A, Lautenschlager C, Wurl $\mathrm{P}$ and Taubert $\mathrm{H}$. Elevated expression of microRNAs $155,203,210$ and 222 in pancreatic tumors is associated with poorer survival. Int J Cancer. 2010;126:73-80.

[14] Shibuya H, Iinuma H, Shimada R, Horiuchi A and Watanabe T. Clinicopathological and prognostic value of microRNA-21 and microRNA-155 in colorectal cancer. Oncology. 2010;79: 313-20.

[15] Chen J, Wang B C and Tang J H. Clinical significance of MicoRNA-155 expression in human breast cancer. J Surg Oncol. 2011.

[16] Yanaihara N, Caplen N, Bowman E, Seike M, Kumamoto K, Yi M, Stephens R M, Okamoto A, Yokota J, Tanaka T, Calin G A, Liu C G, Croce C M and Harris C C. Unique microRNA molecular profiles in lung cancer diagnosis and prognosis. Cancer Cell. 2006;9:189-98.

[17] Heegaard N H, Schetter A J, Welsh J A, Yoneda M, Bowman E D and Harris C C. Circulating micro-RNA expression profiles in early stage nonsmall cell lung cancer. Int $\mathrm{J}$ Cancer. 2012;130:1378-86.

[18] Voortman J, Goto A, Mendiboure J, Sohn J J, Schetter A J, Saito M, Dunant A, Pham T C, Petrini I, Lee A, Khan M A, Hainaut P, Pignon J P, Brambilla E, Popper H H, Filipits M, Harris C C and Giaccone G. MicroRNA expression and clinical outcomes in patients treated with adjuvant chemotherapy after complete resection of non-small cell lung carcinoma. Cancer Res. 2010;70:8288-98.

[19] Stroup D F, Berlin J A, Morton S C, Olkin I, Williamson G D, Rennie D, Moher D, Becker B J, Sipe T A and Thacker $S$ B. Meta-analysis of observational studies in epidemiology: a proposal for reporting. Meta-analysis Of Observational Studies in Epidemiology (MOOSE) group. JAMA. 2000;283: 2008-12.

[20] Parmar M K, Torri V and Stewart L. Extracting summary statistics to perform meta-analyses of the published literature for survival endpoints. Stat Med. 1998;17:2815-34.

[21] Hamano R, Miyata H, Yamasaki M, Kurokawa Y, Hara J, Moon J H, Nakajima K, Takiguchi S, Fujiwara Y, Mori M and Doki Y. Overexpression of miR-200c induces chemoresistance in esophageal cancers mediated through activation of the Akt signaling pathway. Clin Cancer Res. 2011;17:302938.

[22] Kong X, Du Y, Wang G, Gao J, Gong Y, Li L, Zhang Z, Zhu J, Jing Q, Qin Y and Li Z. Detection of differentially expressed microRNAs in serum of pancreatic ductal adenocarcinoma patients: miR-196a could be a potential marker for poor prognosis. Dig Dis Sci. 2011;56:602-9. 
[23] Lawrie C H, Soneji S, Marafioti T, Cooper C D, Palazzo S, Paterson J C, Cattan H, Enver T, Mager R, Boultwood J, Wainscoat J S and Hatton C S. MicroRNA expression distinguishes between germinal center B cell-like and activated B cell-like subtypes of diffuse large B cell lymphoma. Int J Cancer. 2007;121:1156-61.

[24] Lawrie C H, Gal S, Dunlop H M, Pushkaran B, Liggins A P, Pulford K, Banham A H, Pezzella F, Boultwood J, Wainscoat J S, Hatton C S and Harris A L. Detection of elevated levels of tumour-associated microRNAs in serum of patients with diffuse large B-cell lymphoma. Br J Haematol. 2008;141:6725 .

[25] Wang Y, Li Z, He C, Wang D, Yuan X, Chen J and Jin J. MicroRNAs expression signatures are associated with lineage and survival in acute leukemias. Blood Cells Mol Dis. 2010; 44:191-7.

[26] Zhao J J, Lin J, Lwin T, Yang H, Guo J, Kong W, Dessureault S, Moscinski L C, Rezania D, Dalton W S, Sotomayor E, Tao $\mathrm{J}$ and Cheng $\mathrm{J}$ Q. microRNA expression profile and identification of miR-29 as a prognostic marker and pathogenetic factor by targeting CDK6 in mantle cell lymphoma. Blood. 2010; 115:2630-9.

[27] Caponi S, Funel N, Frampton A E, Mosca F, Santarpia L, Van der Velde A G, Jiao L R, De Lio N, Falcone A, Kazemier G, Meijer G A, Verheul H M, Vasile E, Peters G J, Boggi U and Giovannetti E. The good, the bad and the ugly: a tale of miR$101, \mathrm{miR}-21$ and miR-155 in pancreatic intraductal papillary mucinous neoplasms. Ann Oncol. 2013;24:734-41.

[28] Cui E H, Li H J, Hua F, Wang B, Mao W, Feng X R, Li J Y and Wang $X$. Serum microRNA $125 \mathrm{~b}$ as a diagnostic or prognostic biomarker for advanced NSCLC patients receiving cisplatinbased chemotherapy. Acta Pharmacol Sin. 2013;34:309-13.

[29] Kim B H, Hong S W, Kim A, Choi S H and Yoon S O. Prognostic implications for high expression of oncogenic microRNAs in advanced gastric carcinoma. J Surg Oncol. 2012.

[30] Liu R, Liao J, Yang M, Shi Y, Peng Y, Wang Y, Pan E, Guo W, $\mathrm{Pu} \mathrm{Y}$ and Yin L. Circulating miR-155 expression in plasma: a potential biomarker for early diagnosis of esophageal cancer in humans. J Toxicol Environ Health A. 2012;75:1154-62.

[31] Donnem T, Fenton C G, Lonvik K, Berg T, Eklo K, Andersen S, Stenvold H, Al-Shibli K, Al-Saad S, Bremnes R M and Busund L T. MicroRNA signatures in tumor tissue related to angiogenesis in non-small cell lung cancer. PLoS One. 2012; 7:e29671.

[32] Sun Y, Wang M, Lin G, Sun S, Li X, Qi J and Li J. Serum microRNA-155 as a potential biomarker to track disease in breast cancer. PLoS One. 2012;7:e47003.

[33] Donnem T, Eklo K, Berg T, Sorbye S W, Lonvik K, Al-Saad S, Al-Shibli K, Andersen S, Stenvold H, Bremnes R M and Busund L T. Prognostic impact of MiR-155 in non-small cell lung cancer evaluated by in situ hybridization. J Transl Med.
2011;9:6.

[34] Lee J H, Voortman J, Dingemans A M, Voeller D M, Pham T, Wang $\mathrm{Y}$ and Giaccone G. MicroRNA expression and clinical outcome of small cell lung cancer. PLoS One. 2011;6:e21300.

[35] Raponi M, Dossey L, Jatkoe T, Wu X, Chen G, Fan H and Beer D G. MicroRNA classifiers for predicting prognosis of squamous cell lung cancer. Cancer Res. 2009;69:5776-83.

[36] Rossi S, Shimizu M, Barbarotto E, Nicoloso M S, Dimitri F, Sampath D, Fabbri M, Lerner S, Barron L L, Rassenti L Z, Jiang L, Xiao L, Hu J, Secchiero P, Zauli G, Volinia S, Negrini M, Wierda W, Kipps T J, Plunkett W, Coombes K R, Abruzzo L V, Keating M J and Calin G A. microRNA fingerprinting of CLL patients with chromosome 17p deletion identify a miR-21 score that stratifies early survival. Blood. 2010;116:945-52.

[37] Saito M, Schetter A J, Mollerup S, Kohno T, Skaug V, Bowman E D, Mathe E A, Takenoshita S, Yokota J, Haugen A and Harris $\mathrm{C} \mathrm{C}$. The association of microRNA expression with prognosis and progression in early-stage, non-small cell lung adenocarcinoma: a retrospective analysis of three cohorts. Clin Cancer Res. 2011;17:1875-82.

[38] Huang Y H, Lin K H, Chen H C, Chang M L, Hsu C W, Lai $\mathrm{M}$ W, Chen T C, Lee W C, Tseng Y H and Yeh C T. Identification of postoperative prognostic microRNA predictors in hepatocellular carcinoma. PLoS One. 2012;7:e37188.

[39] Ishihara K, Sasaki D, Tsuruda K, Inokuchi N, Nagai K, Hasegawa H, Yanagihara K and Kamihira S. Impact of miR155 and miR-126 as novel biomarkers on the assessment of disease progression and prognosis in adult T-cell leukemia. Cancer Epidemiol. 2012;36:560-5.

[40] Maj J, Jankowska-Konsur A, Sadakierska-Chudy A, Noga L and Reich A. Altered microRNA expression in mycosis fungoides. Br J Dermatol. 2012;166:331-6.

[41] Papaconstantinou I G, Manta A, Gazouli M, Lyberopoulou A, Lykoudis P M, Polymeneas G and Voros D. Expression of micrornas in patients with pancreatic cancer and its prognostic significance. Pancreas. 2013;42:67-71.

[42] Yan L X, Huang X F, Shao Q, Huang M Y, Deng L, Wu Q L, Zeng Y X and Shao J Y. MicroRNA miR-21 overexpression in human breast cancer is associated with advanced clinical stage, lymph node metastasis and patient poor prognosis. RNA. 2008;14:2348-60.

[43] Jiang J, Gusev Y, Aderca I, Mettler T A, Nagorney D M, Brackett D J, Roberts L R and Schmittgen T D. Association of MicroRNA expression in hepatocellular carcinomas with hepatitis infection, cirrhosis, and patient survival. Clin Cancer Res. 2008;14:419-27.

[44] Fu X, Han Y, Wu Y, Zhu X, Lu X, Mao F, Wang X, He X and Zhao Y. Prognostic role of microRNA-21 in various carcinomas: a systematic review and meta-analysis. Eur J Clin Invest. 2011;41:1245-53. 


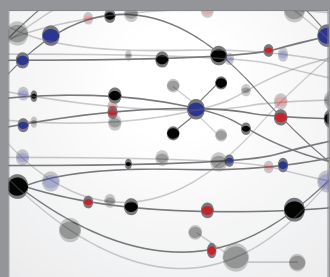

The Scientific World Journal
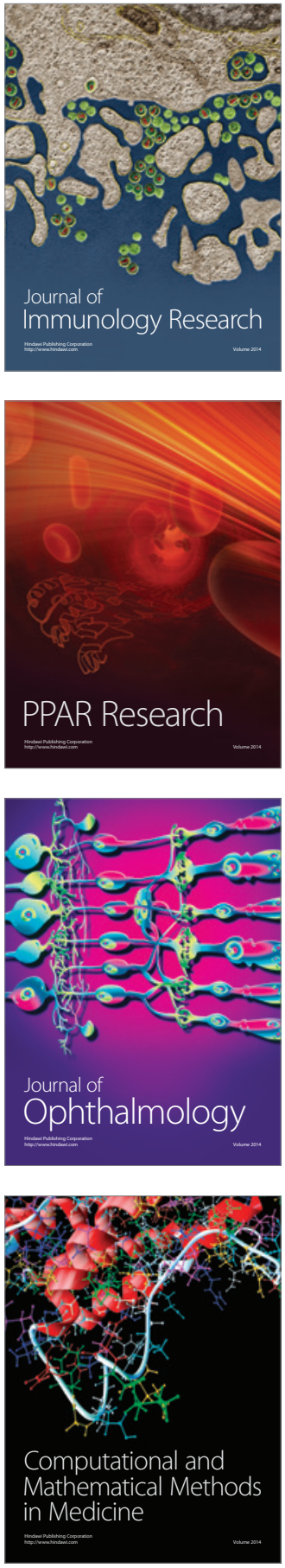

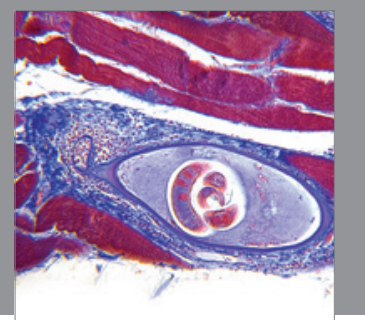

Gastroenterology

Research and Practice
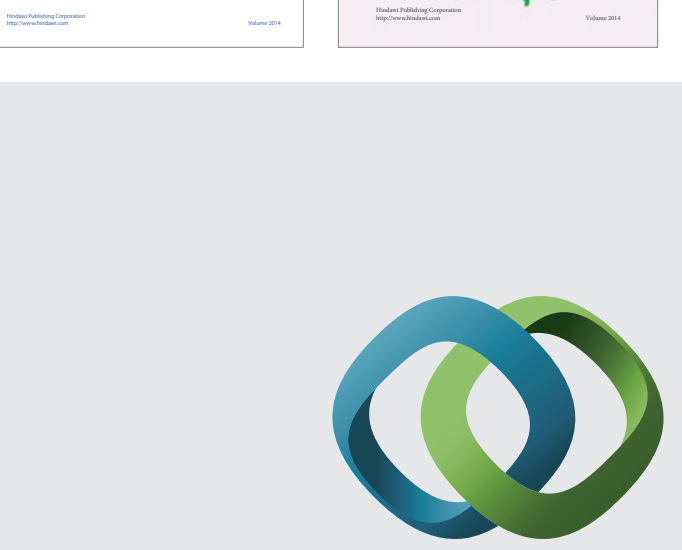

\section{Hindawi}

Submit your manuscripts at

http://www.hindawi.com
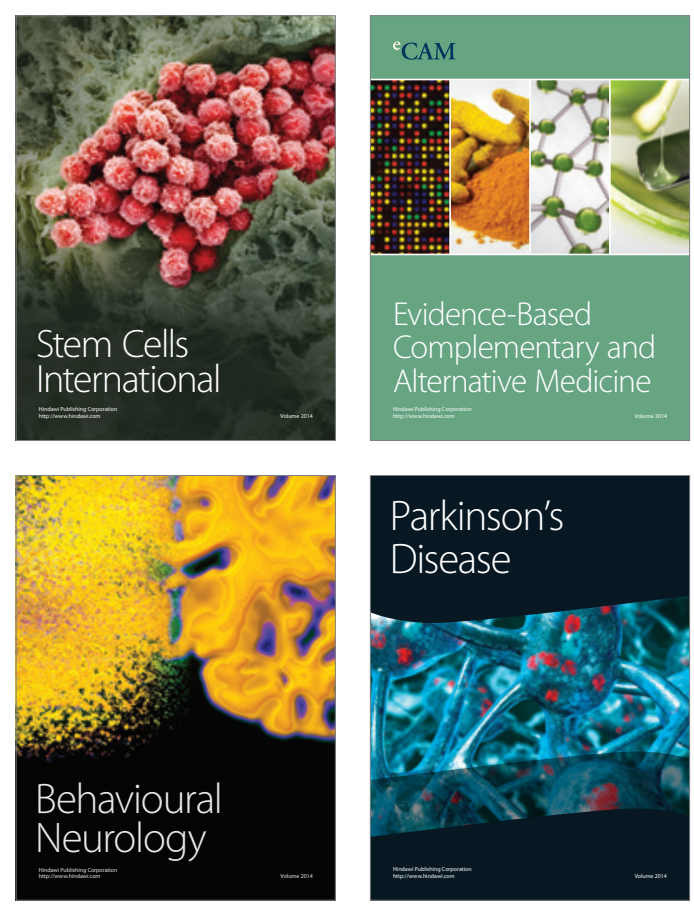

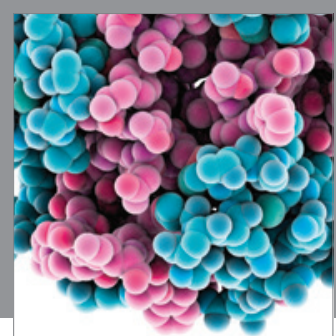

Journal of
Diabetes Research

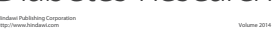

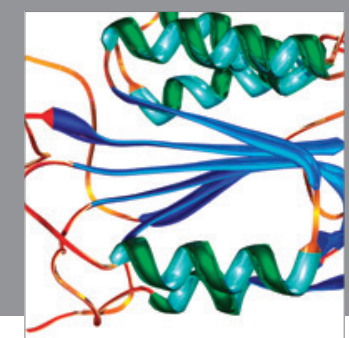

Disease Markers
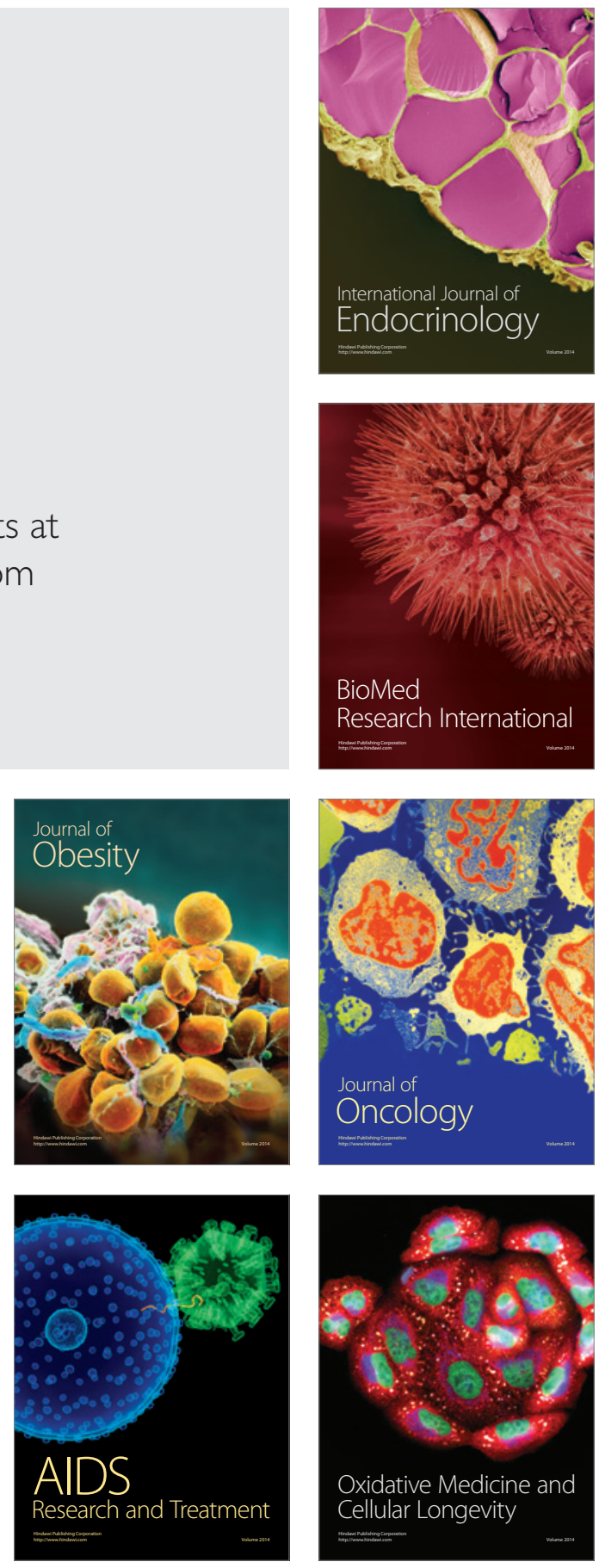